\title{
Distal radyoulnar eklemde romatoid artrit sorunları
}

\author{
Rheumatoid arthritis problems in the distal radioulnar joint \\ Okan Aslantürk, Emre Ergen, Kadir Ertem \\ İnönü Üniversitesi Tıp Fakültesi, Ortopedi ve Travmatoloji Ana Bilim Dalı, Malatya
}

\begin{abstract}
El bileği romatoid artritte en sık etkilenen eklemlerden biridir. Distal radyoulnar eklem hastalığın erken döneminden itibaren tutulmaktadır. Romatoid artrit, distal radyoulnar eklemde hem instabiliteye hem de artroza neden olmaktadır. Tedavi hastalığın evresine, artroz seviyesine, hastanın yaşına ve aktivite düzeyine göre belirlenir. Erken evrelerde konservatif tedaviler uygulanırken, ileri evrede cerrahi tedaviler uygulanmaktadır.

Anahtar sözcükler: romatoid artrit; el bilek; Darrach; Sauvé-Kapanji; distal ulna
\end{abstract}

\begin{abstract}
The wrist is one of the most affected joints in rheumatoid arthritis. Distal radioulnar joint is involved even in the early stage of the disease. Rheumatoid arthritis causes both instability and arthrosis in the distal radioulnar joint. The treatment is determined due to stage of the disease, the stage of arthrosis, the age and activity level of the patient. While conservative treatments are used in the early stages, surgical treatments are used in the advanced stages.

Key words: rheumatoid arthritis; wrist; Darrach; Sauvé-Kapanji; distal ulna
\end{abstract}

$\mathbf{R}$ omatoid artrit (RA) en sık görülen enflamatuvar artrittir. Romatoid artrit birçok eklemi tutar ve ilerleyici olarak eklem harabiyetine neden olur. Romatoid artrit hastalarının büyük çoğunluğunda el bilek eklemi etkilenmektedir. ${ }^{[1]}$ Distal radyoulnar eklem (DRUE) hastalığın erken döneminde $\% 31$, geç döneminde ise $\% 75$ oranında etkilenmektedir. ${ }^{[2]}$ Bazı hastalarda DRUE tutulumu RA'nın ilk bulgusu olabilir. ${ }^{[3]}$

Romatoid artritte, DRUE'nin hem statik (kemik ve bağlar) hem de dinamik (kaslar) stabilizatörleri kronik enflamatuvar süreçten etkilenmektedir ve böylece DRUE'de instabilite ortaya çıkmaktadır. ${ }^{[4]}$ Kemik erozyonları, bağ ve tendon hasarları nedeniyle DRUE çıkıklarına neden olabilmektedir. Bu bölümde RA hastalarında DRUE problemlerinin klinik özellikleri, radyolojik özellikleri ve tedavisinden bahsedilecektir.

\section{Klinik Değerlendirme}

Hastalar genellikle ağrı ve güçsüzlük şikâyeti ile başvururlar. ${ }^{[3]}$ El bilek hareketleri, özellikle supinasyon kısıtlıdır. ${ }^{[5]}$ Karpal kemiklerin volare subluksasyonu ve supinasyonu nedeniyle distal ulnanın çıkıntılı görünmesine (kaput ulna sendromu) neden olur. ${ }^{[3]} \mathrm{Bu}$ sendromda, sinovite bağlı olarak gelişen kemik çıkıntıları nedeniyle özellikle beşinci ve dördüncü parmakların ekstansör tendonlarında rüptür (Vaughan-Jackson sendromu) görülebilir. ${ }^{[6]}$

Hasta muayenesi sırasında eklem hareket açıklığı, el bileği deformitesi ve DRUE instabilitesi olup olmadığı dikkatlice muayene edilmelidir. Romatoid artrit omuz, dirsek, karpal ve metakarpofalangeal eklemleri de etkileyebileceği için bu eklemlerin muayeneleri de mutlaka yapılmalıdır. Ayrıca duyu ve motor sinir muayeneleri de yapılmalıdır.

\section{Radyolojik Değerlendirme}

Standart düz radyografi görüntülerinde saptanan kemik erozyonları, artrozu değerlendirmede ve tedavi planını yapmak için çok önemlidir. Eklem daralması DRUE'de en sık görülen erken dönem radyolojik bulgulardandır. ${ }^{[7]}$ Sigmoid çentik ve/veya ulna başında erozyonlar görülebilir. İlerleyen dönemlerde ulna başının dorsale çıkığı yan grafilerde görülebilir. ${ }^{[3]}$ Manyetik rezonans (MR) görüntüleme ve bilgisayarlı tomografi (BT) gibi ileri tetkiklere genellikle gerek yoktur. Ancak

- Illetişim adresi: Dr. Okan Aslantürk, İnönü Üniversitesi Tıp Fakültesi, Ortopedi ve Travmatoloji Ana Bilim Dalı, Elazı̆̆ Yolu 15 . Km 44280 Battalgazi, Malatya Tel: 0506 - 3297616 e-posta: okaslanturk@hotmail.com

- Geliș tarihi: 24 Mayıs $2021 \quad$ Kabul tarihi: 31 Mayıs 2021

ORCID iD: Okan Aslantürk, 0000-0001-6167-3952 • Emre Ergen, 0000-0002-6452-2401 • Kadir Ertem, 0000-0002-8892-494X 

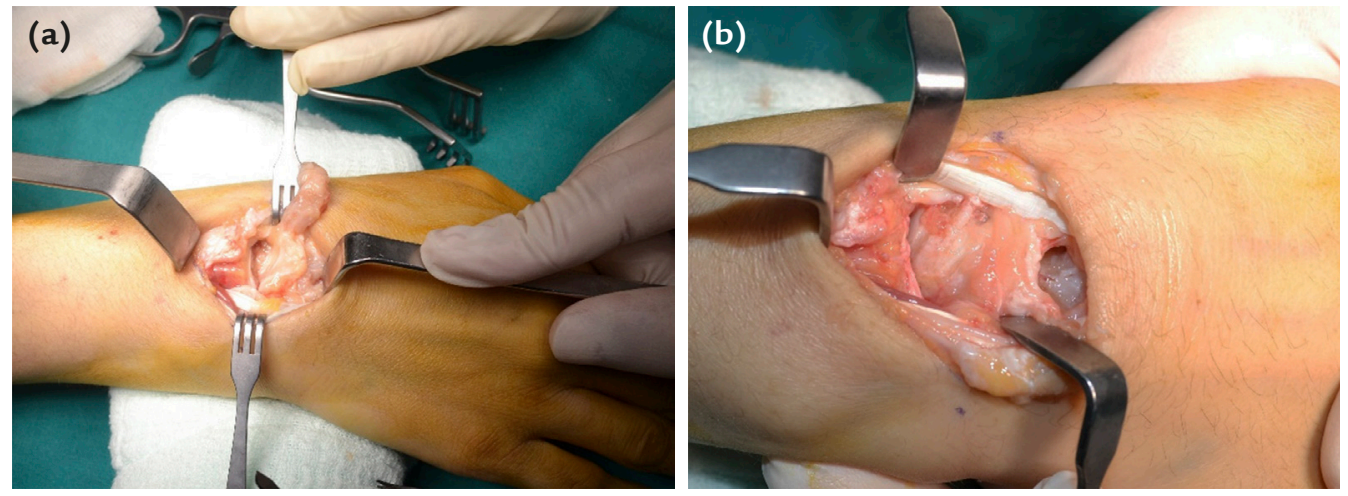

Şekil 1. a, b. El bilek sinoviti (a), sinoviyektomi sonrası görünüm (b).

yumuşak dokuları ve tenosinoviti değerlendirmek için MR kullanılabilir. ${ }^{[8]}$ Ayrıca erken evrelerde kıkırdak hasarını değerlendirmek için de kullanılabilir.

\section{TEDAVi}

Romatoid artritin günümüzde bilinen kesin bir tedavisi yoktur. Tedavinin amacı hastalığın ilerlemesini yavaşlatmak, hastanın ağrısını azaltmak, eklem hareketlerini korumak, deformite gelişmesini önlemek ve deformite gelişmiş ise deformiteyi düzeltmektir. Bu hastalar romatoloji uzmanı, fizik tedavi uzmanı, fizyoterapist ve el cerrahından oluşan bir ekip tarafından multidisipliner olarak tedavi edilmelidir. Hastalığın evresine göre konservatif ya da cerrahi tedaviler uygulanabilir.

\section{Konservatif Tedaviler}

Romatoid artritin erken evresinde medikal tedavi, fizyoterapi ve breysleme gibi konservatif tedaviler uygulanmaktadır. Hastalığın ilerlemesini önlemek için kullanılan hastalık modifiye edici anti-romatizmal ilaçlar (örneğin; metotreksat, sulfasalazin, hidrokinolon, leflunomid vb.) ve biyolojik anti-romatizmal ilaçlar (örneğin; etanercept, tocilizumab vb.) sinovit ve eklem erozyonunu da azaltmaktadır. ${ }^{[9-11]}$ Eklem içi steroid enjeksiyonunun ağrıları azaltabileceği ve hastada rahatlama sağlayabileceği de bildirilmiştir. ${ }^{[12]}$

El bilek atelleri (splintleri) hastanın ağrılarını azaltmakta ve fonksiyonları düzeltmekte yararlı olabilir. ${ }^{[7]}$ Ancak literatürde atel tedavisinin etkin olmadığını gösteren çalışmalar da mevcuttur. ${ }^{[13]}$

\section{Cerrahi Tedaviler}

Hastalarda uygun konservatif tedaviye rağmen ağrı, fonksiyon bozukluğu ve deformite mevcutsa hastaya cerrahi müdahaleler düşünülmelidir. Belirgin ağrısı olmayan hastalara sadece deformiteyi düzeltmek için cerrahi önerilmemektedir. ${ }^{[14]}$ Literatürde cerrahinin zamanlaması ile ilgili kesin bir görüş birliği olmamasına rağmen en az 3-6 aylık konservatif tedaviye yanıt vermeyen ağrılı olgulara cerrahi yapılması önerilmektedir. ${ }^{[3,6,7,15]}$ Ancak tendon rüptürü gibi durumlarda geciktirmeden cerrahi tedavi ile tendon onarım veya rekonstrüksiyonu yapılmalıdır.

Cerrahi tedavinin amacı ağrıyı gidermek, eklem fonksiyonlarının korunmasını sağlamak, deformiteyi düzeltmek ve el bileğinin kozmetik bir görüntüye kavuşmasını sağlamaktır. ${ }^{[3]}$ Hastalarda ileri derece kontraktür, artroz ve subluksasyon gelişmeden yapılan cerrahi tedavilerden daha iyi sonuç alındığı bildirilmiştir. ${ }^{[16]}$ Literatürde DRUE sorunu olan RA hastalarında birçok cerrahi tedavi yöntemi tariflenmiştir.

\section{Sinoviyektomi ve tenosinoviyektomi}

Uygun medikal tedavilere rağmen el bileğinde şişliği ve ağrısı devam eden ancak eklemde harabiyeti gelişmemiş hastalarda tek başına uygulanabilir. Ayrıca diğer cerrahi prosedürlerde gerekli durumlarda eklenebilirler. Hastalığın erken evresinde yapılan tenosinoviyektominin tendon rüptürlerini önlediği düşünülmektedir. ${ }^{[17]}$ Yapılan çalışmalarda tenosinoviyektomi sonrası tenosinovit tekrarlama ve tendon rüptürü oranının daha düşük olduğu gösterilmiştir. ${ }^{[3,18,19]}$ Sinoviyektomi sonrası sinovit tekrarlasa bile daha az şiddetli olarak tekrarladığı gösterilmiştir. ${ }^{[5]}$

Sinoviyektomi işlemi dorsalden açık (Şekil 1) ya da artroskopik olarak yapılabilir. Artroskopik tekniğin daha minimal invaziv olması, daha küçük kesilerden yapılması ve daha erken rehabilitasyona başlanabilmesi gibi avantajları mevcuttur. ${ }^{[20]}$ Tenosinoviyektomi için ise etkilenen tendonlara bağlı olarak volar ya da dorsal açık insizyonlar kullanılabilir (Şekil 2).

\section{Tendon onarımı, rekonstrüksiyonu ve transferi}

Romatoid artrit hastalarında genellikle bir travma olmadan spontan tendon rüptürleri görülmektedir. 

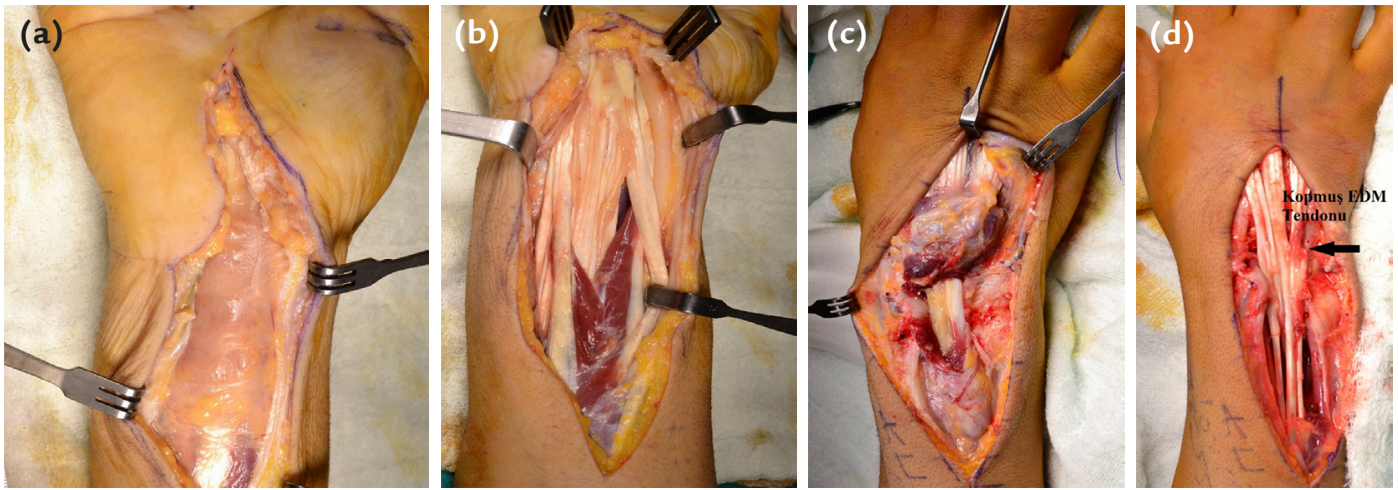

Şekil 2. a-d. El bileğinin fleksör tendonlarının tenosinoviti (a), tenosinoviyektomi sonrası görünüm (b). El bileğinin ekstansör tendonlarının tenosinoviti (c), tenosinovivektomi sonrası tendonların görünümü ve kopmuş olan EDM tendonu (d). EDM, ekstansör dijiti minimi.
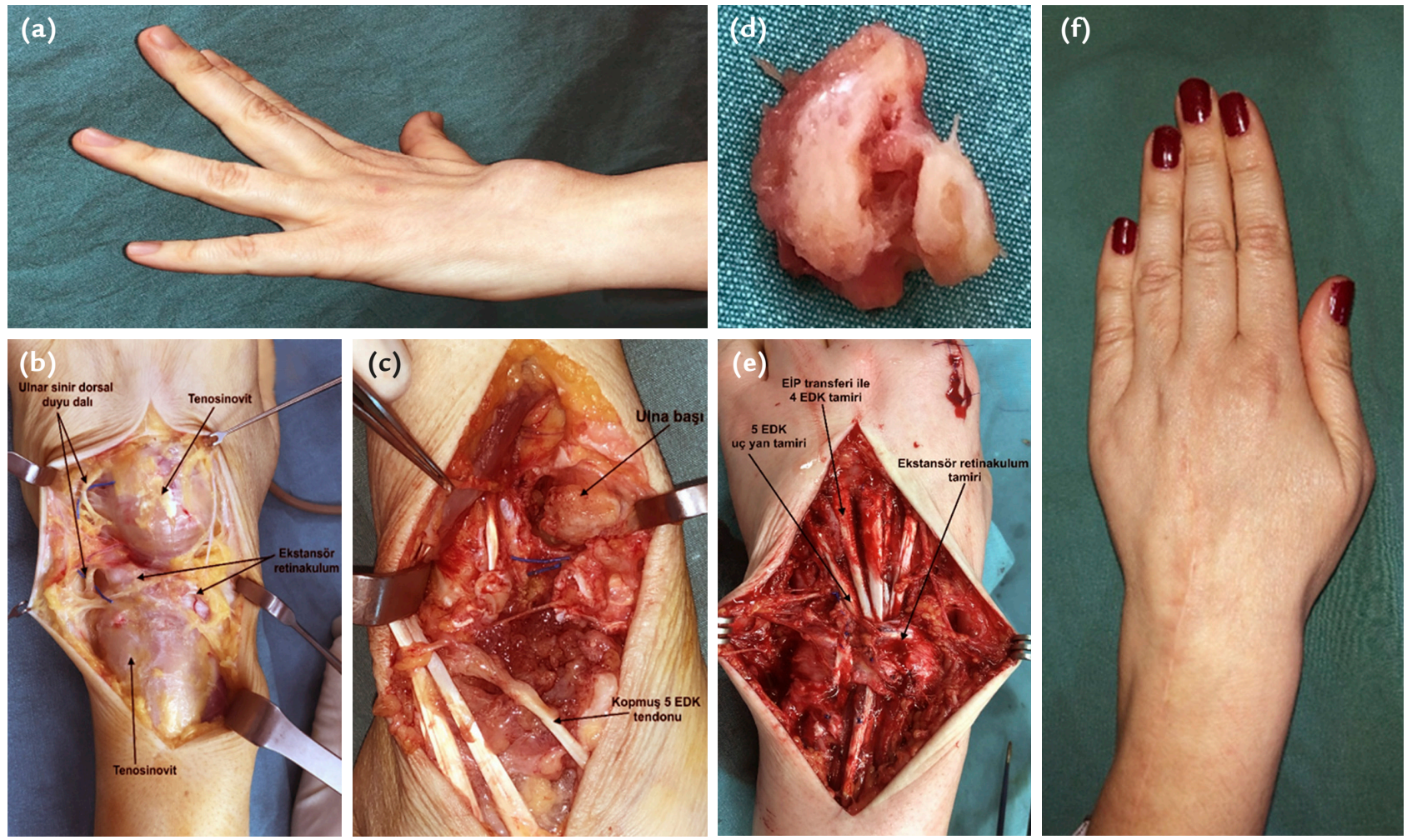

Şekil 3. a-f. El bileği dorsalinde tenosivit şişliği ve 4-5. parmaklarda ekstansör dijitorum kommunis tendon rüptürüne bağlı ekstansiyon kaybı (a). Dorsal yaklaşım sonrası tenosinovit kitlesi, ekstansör retinakulum ve ulnar sinir dorsal duyusal dalı görülmektedir (b). Tenosinoviyektomi sonrası ulna başı ve kopmuş olan beşinci parmak ekstansör dijitorum kommunisin tendonu görülmektedir (c). Çıkarılmış olan ulna başında kıkırdağın olmadığı görülmektedir (d). EiP transferi ile dördüncü parmak EDK tendon rekonstrüksiyonu, beşinci parmak EDK tendonunun dördüncü parmak EDK'ya uç yan pulvertaft yöntemi ile tamiri; ekstansör retinakulum tamiri görülmektedir (e). Bir yıl sonra parmak ekstansiyonlarının tam olduğu görülmektedir (f)(EiP, ekstansör indisis proprius; EDK, ekstansör dijitorum kommunis). (Prof. Dr. Kahraman Öztürk’ün arşivinden izni ile alınmıştır.)

Bu hastalarda en sık ekstansör dijiti minimi (EDM) (Şekil 2d) ile 4. ve 5. parmak ekstansör dijitorum kommunis (EDK) tendonlarında rüptür görülmektedir. ${ }^{[21]}$ Fleksör tendonlardan ise en sık fleksör pollisis longus (FPL) ve 4. parmağın fleksör dijitorum profundus (FDP) tendonlarında rüptür görülmektedir. ${ }^{[22]}$ RA hastalarında meydana gelen rüptürlerde genellikle uç uca primer onarım genellikle mümkün değildir. ${ }^{[3,7]} \mathrm{Bu}$ nedenle tendon transferi, greftleme ve uç-yan tendon onarımı gibi yöntemlerle fonksiyonlar yeniden kazandırılmaya çalışılır (Şekil 3b-f). ${ }^{[3-7]}$ 

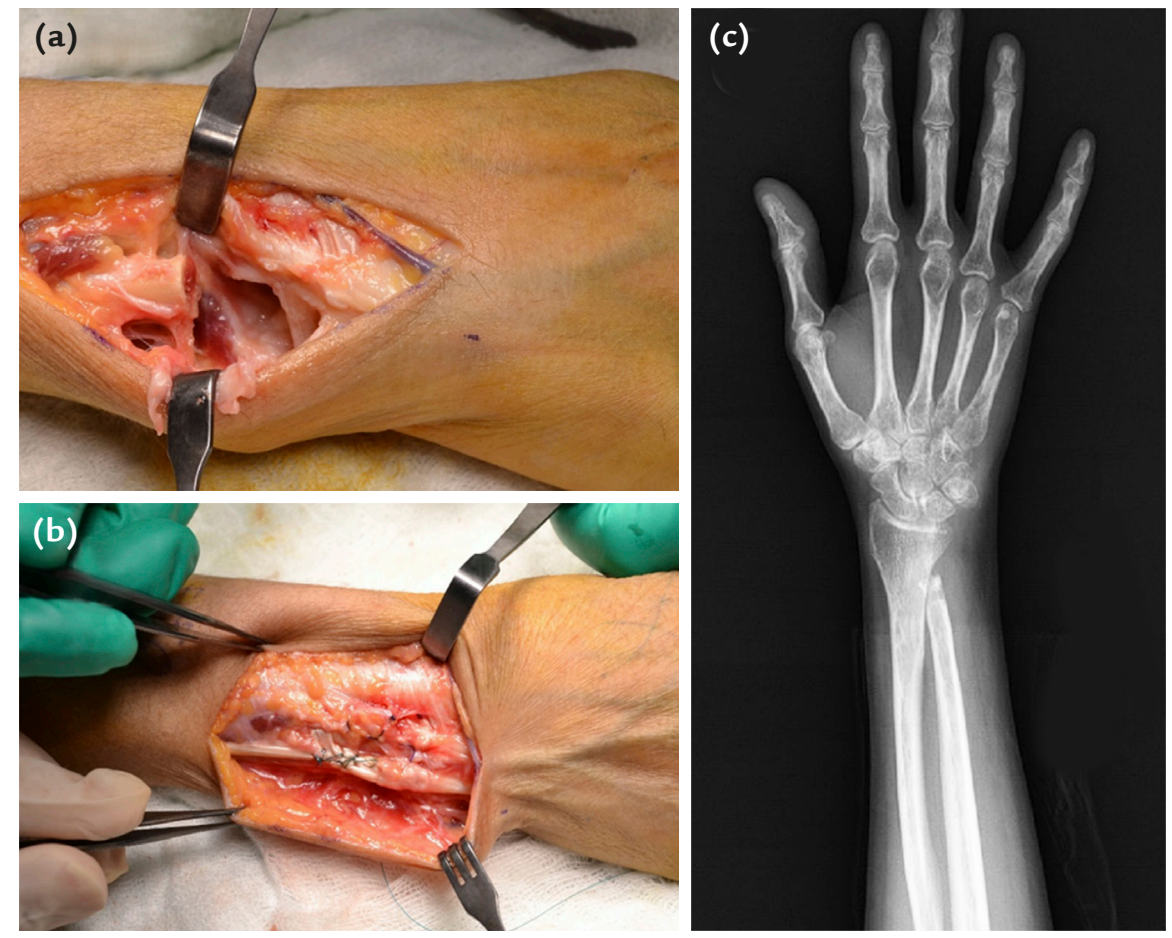

Şekil 4. a-c. Distal ulna rezeksiyonu sonrası güdüğün görünümü (a). Ekstansör karpi ulnaris tenodezi (b). Ameliyat sonrası röntgen görüntüsünde radyoulnar impingement görülmektedir (c).

Tendon rüptürü olan hastalarda tenosinoviyektomi yapılmalı ve rüptüre neden olan kemik çıkıntılar da temizlenmelidir (Şekil 3a-c). Kaput ulna sendromunda tendon rüptürü görüldüyse distal ulna eksizyonu da aynı seansta yapılmalıdır (Şekil 3d). Ekstansör tendon rüptürlerinde mümkünse uç uca tamir yapılabilir. Bunun mümkün olmadığı durumlarda rüptüre olan tendonun distal güdüğü yanındaki tendona sütüre edilebilir. Birden fazla tendon rüptürü olması durumunda (4. ve 5. EDK tendonları gibi), tendonlardan birine tendon transferi (indisis proprius tendonu [EIP] en sık kullanılan) yapılabilir ve diğer tendonun distal güdüğü bu tendona sütüre edilebilir (Şekil 3e, 3f). Üç ya da daha fazla tendon rüptüre olmuş ise bu durumda EiP tendon tranferi yeterli olmayacağı için fleksör tendonlar transfer edilebilir. ${ }^{[23]}$

\section{Distal ulna rezeksiyonu (Darrach prosedürü)}

Distal ulna rezeksiyonu ilk olarak 1644 yılında Severinus tarafından tariflenmiş olsa da, Darrach tarafından popülerize edilmiş bir yöntemdir. ${ }^{[3,6]}$ Distal radyoulnar eklemde artrozu olan karpal instabilitesi olmayan düşük beklentili yaşlı hastalara önerilmektedir. ${ }^{[3,6,7]}$ Genç hastalarda (<45 yaş) ve karpal instabilitesi olan hastalara uygulandığında ise kötü sonuçlar bildirilmiştir. ${ }^{[24]}$
Cerrahi sırasında mümkün olduğu kadar az kemik rezeksiyonu yapılmasına özen gösterilmelidir. Radiusun sigmoid çentiğinin hemen proksimalinden ince bir testere ile rezeksiyon yapılmalıdır (Şekil 4). Yapılan çalışmalarda 2-3 cm'den fazla rezeksiyon yapılmasının ulnar translasyona neden olabileceği bildirilmiştir. ${ }^{[6,25]}$ Etraf yumuşak dokulara zarar vermemek, tendon rüptürüne neden olmamak için kemik uçlarında çıkıntı olmamasına dikkat edilerek düzeltilmelidir. Distal ulna güdüğünün stabilizasyonu için sıklıkla tenodez uygulanmaktadır, bu işlem için en sık ekstansör karpi ulnaris (EKU) tendonu kullanılmaktadır (Şekil 4b). ${ }^{[3]}$ Proksimal ulna güdüğgunün impingementi en sık bildirilen komplikasyondur (Şekil 4c). Darrach prosedürünün başarısız olduğu durumlarda distal ulna artroplastisi, kısmi ya da total el bilek artrodezi ameliyatları gerekebilir. ${ }^{[3]}$

\section{Sauvé-Kapandji prosedürü}

Distal radyoulnar eklem artrodezi yapılan bir cerrahi tekniktir. Ön kol rotasyonunu korumak için artrodez seviyesinin proksimalinden ulnadan segment rezeksiyonu yapılır. ${ }^{[7]}$ Aktif ve genç hastalara önerilmektedir. Sauvé-Kapandji tekniğinin karpal translasyonu önlediği iddia edilse de bu konu tartışmalıdır. ${ }^{[6]}$ Romatoid artrit hastalarında Darrach prosedürüne göre daha iyi 
sonuçlar elde edildiğini bildiren çalışmalar olsa da her iki yöntem arasında fark olmadığını bildiren çalışmalar da mevcuttur. ${ }^{[6,25]}$ Yapılan çalışmalarda hastalarda Sauvé-Kapandji prosedürü sonrası ağrının azaldığı, eklem hareket açıklığının ve kavrama gücünün arttığı gösterilmektedir. ${ }^{[26]}$ Proksimal ulna güdügünün instabilitesi en sık bildirilen komplikasyondur. ${ }^{[27]}$

\section{Hemirezeksiyon interpozisyon artroplastisi}

Illk olarak Bower tarafından tanımlanmış olan bu yöntemde, distal ulnanın radiusla eklem yapan kısmı oblik bir kesi ile rezeke edilerek pronator kuadratus interpozisyonu yapılırken, triangular fibrokartilaj kompleks (TFKK) yapışma yeri ve ulnar stiloid korunmaktadir. $^{[28]}$ Daha sonra Watson tarafindan modifiye edilerek distal ulnanın şeklinin distal radiusa uyacak şekilde şekillendirilmesi amaçlanmıştır. ${ }^{[29]}$ Bu tekniklerin uygulanabilmesi için TFKK'nin sağlam ya da tamir edilebilir durumda olması gerekmektedir. Her iki yöntemde de yazarlar iyi sonuçlar bildirmişlerdir. ${ }^{[28,29]}$ Bildirilen iyi sonuçlara rağmen günümüzde bu teknikler sık tercih edilen teknikler değillerdir.

\section{Distal ulna artroplastisi}

Distal radyoulnar eklem artrozunda kısmi ya da total eklem protezleri nispeten yeni teknikler olmasına rağmen literatürdeki çalışmalarda iyi sonuçlar bildirilmektedir. ${ }^{[30,31]}$ Diğer tekniklerde önemli bir sorun olan distal ulna ya da proksimal ulna instabilitesinin, özellikle total DRUE protezleri için bir sorun olmadığı bildirilmektedir. ${ }^{[31]}$ Protezlerle ilgili en büyük endişe özellikle RA gibi durumlarda daha sık görülen gevşeme problemleridir. ${ }^{[32]}$ Distal ulna protezi ile ilgili olarak bildiğimiz kadarıyla literatürde henüz orta-uzun dönem takip sonuçlarına ilişkin veri yoktur. Mevcut çalışmaların birçoğu kısa dönem takip ve sınırlı sayıda hasta ile yapılmıştır.

\section{KAYNAKLAR}

1. De Smet $L$. The distal radioulnar joint in rheumatoid arthritis. Acta Orthop Belg 2006;72(4):381-6. https://pubmed.ncbi. nlm.nih.gov/17009815/

2. Leak RS, Rayan GM, Arthur RE. Longitudinal radiographic analysis of rheumatoid arthritis of the hand and wrist. J Hand Surg Am 2003;28(3):427-34. Crossref

3. Lee SK, Hausman MR. Management of the distal radioulnar joint in rheumatoid arthritis. Hand Clin 2005;21(4):577-89. Crossref

4. Weiler PJ, Bogoch ER. Kinematics of the distal radioulnar joint in rheumatoid arthritis: an in vivo study using centrode analysis. J Hand Surg Am 1995;20(6):937-43. Crossref

5. Clawson MC, Stern PJ. The distal radioulnar joint complex in rheumatoid arthritis: an overview. Hand Clin 1991;7(2):37381. Crossref

6. Murray PM. Current concepts in the treatment of rheumatoid arthritis of the distal radioulnar joint. Hand Clin 2011;27(1):49-55. Crossref
7. Rizzo M, Cooney WP 3rd. Current concepts and treatment for the rheumatoid wrist. Hand Clin 2011;27(1):57-72. Crossref

8. Lisbona MP, Maymo J, Perich J, Almirall M, Carbonell J. Rapid reduction in tenosynovitis of the wrist and fingers evaluated by $\mathrm{MRI}$ in patients with rheumatoid arthritis after treatment with etanercept. Ann Rheum Dis 2010;69(6):1117-22. Crossref

9. Bathon JM, Martin RW, Fleischmann RM, Tesser JR, Schiff $\mathrm{MH}$, Keystone EC, Genovese MC, Wasko MC, Moreland LW, Weaver AL, Markenson J, Finck BK. A comparison of etanercept and methotrexate in patients with early rheumatoid arthritis. N Engl J Med 2000;343(22):1586-93. Crossref

10. Scott DL, Kingsley GH. Tumor necrosis factor inhibitors for rheumatoid arthritis. N Engl J Med 2006;355(7):704-12. Crossref

11. Wolfe F, Michaud K. The loss of health status in rheumatoid arthritis and the effect of biologic therapy: a longitudinal observational study. Arthritis Res Ther 2010;12:R35. Crossref

12. Lopes RV, Furtado RN, Parmigiani L, Rosenfeld A, Fernandes ARC, Natour J. Accuracy of intra-articular injections in peripheral joints performed blindly in patients with rheumatoid arthritis. Rheumatology (Oxford) 2008;47(12):1792-4. Crossref

13. Adams J, Burridge J, Mullee M, Hammond A, Cooper C. The clinical effectiveness of static resting splints in early rheumatoid arthritis: a randomized controlled trial. Rheumatology (Oxford) 2008;47(10):1548-53. Crossref

14. BlankJE, Cassidy $C$. The distal radioulnar joint in rheumatoid arthritis. Hand Clin 1996;12(3):499-513. Crossref

15. Ryu J, Saito S, Honda T, Yamamoto K. Risk factors and prophylactic tenosynovectomy for extensor tendon ruptures in the rheumatoid hand. J Hand Surg Br 1998;23(5):658-61. Crossref

16. Ryu J, Patel SM. Rheumatoid arthritis-soft tissue reconstruction. In: Trumble TE, editor. Hand Surgery Update 3. Rosemont (IL): American Society for Surgery of the Hand; 2003. p.535-51.

17. Alderman AK, Ubel PA, Kim HM, Fox DA, Chung KC. Surgical management of the rheumatoid hand: consensus and controversy among rheumatologists and hand surgeons. J Rheumatol 2003;30(7):1464-72. https://www.jrheum.org/ content/30/7/1464.long

18. Clayton ML. Surgical treatment at the wrist in rheumatoid arthritis. J Bone Joint Surg Am 1965;47(4):741-50. Crossref

19. Millender LH, Nalebuff EA, Albin R, Ream JR, Gordon M. Dorsal tenosynovectomy and tendon transfer in the rheumatoid hand. J Bone Joint Surg Am 1974;56(3):601-10. Crossref

20. Park MJ, Ahn JH, Kang JS. Arthroscopic synovectomy of the wrist in rheumatoid arthritis. J Bone Joint Surg Br 2003;85$B(7): 1011-5$. Crossref

21. Norris SH. Surgery for the rheumatoid wrist and hand. Ann Rheum Dis 1990;49(Suppl 2):863-70. Crossref

22. Ertel AN, Millender LH, Nalebuff E, McKay D, Leslie B. Flexor tendon ruptures in patients with rheumatoid arthritis. J Hand Surg Am 1988;13(6):860-6. Crossref

23. Feldon P, Terrono AL, NalebuffEA, Millender LH. Rheumatoid arthritis and other connective tissue diseases. In: Wolfe SW, Hotchkiss RN, Pederson WC, Kozin SH, Cohen MS. Green's Operative Hand Surgery, 7th ed. Philadelphia: Elsevier/ Churchill Livingstone; 2017. p.1993-2065. Crossref

24. Bieber EJ, Linscheid RL, Dobyns JH, Beckenbaugh RD. Failed distal ulna resections. J Hand Surg Am 1998;13(2):193-200. Crossref 
25. Tulipan DJ, Eaton RG, Eberhart RE. The Darrach procedure defended: technique redefined and longterm follow-up. J Hand Surg Am 1991;16(3):438-44. Crossref

26. Carl HM, Lifchez SD. Functional and Radiographic Outcomes of the Sauvé-Kapandji and Darrach Procedures in Rheumatoid Arthritis. J Hand Microsurg 2019;11(2):71-9. Crossref

27. Minami A, Kamiya Y, Tojo Y, Harmon SM, Suda K. Modified Sauvé-Kapandji procedure for the distal radioulnar joint disorders of osteoarthritis and rheumatoid arthritis. J Orthop Sci 2018;23(3):516-20. Crossref

28. Bowers $\mathrm{WH}$. Distal radioulnar joint arthroplasty: the hemiresection-interposition technique. J Hand Surg Am 1985;10:169-78. Crossref
29. Watson HK, Ryu JY, Burgess RC. Matched distal ulnar resection. J Hand Surg Am 1986;11(6):812-7. Crossref

30. Bigorre N, Saint Cast Y, Cesari B, Rabarin F, Raimbeau G. Intermediate term evaluation of the Eclypse distal radio-ulnar prosthesis for rheumatoid arthritis. A report of five cases. Orthop Traumatol Surg Res 2016;102(3):345-9. Crossref

31. Galvis EJ, Pessa J, Scheker LR. Total joint arthroplasty of the distal radioulnar joint for rheumatoid arthritis. J Hand Surg Am 2014;39(9):1699-704. Crossref

32. Adams BD. Complications of wrist arthroplasty. Hand Clin 2010;26(2):213-20. Crossref 